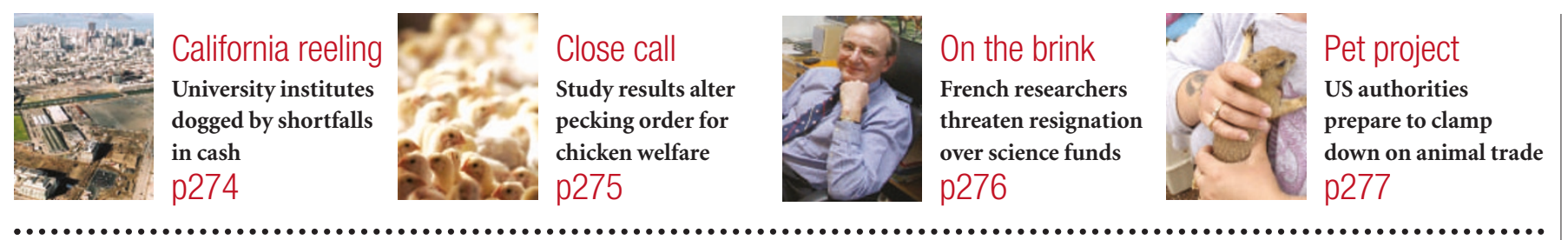

\title{
NASA's drive to revisit the Moon leaves no scope for Hubble
}

Tony Reichhardt, Washington

President George Bush's call last week to return US astronauts to the Moon by 2020 has won him plaudits from the space community. But on 16 January his plan claimed its first high-profile victim when NASA administrator Sean O'Keefe announced that the Hubble Space Telescope will be retired about three years early.

Bush's proposal, which calls for a manned lunar landing sometime between 2015 and 2020, requires the most sweeping overhaul in NASA's history. Researchers contacted by Nature say that with about $\$ 12$ billion earmarked for the project over the next five years, the space agency should have enough money at least to get started on it.

But of this money, Bush's plan includes only $\$ 1$ billion in additional funding, so the space shuttle will be phased out by 2010 . Together with other savings, including drastic cuts in research on the still unfinished International Space Station, the agency should save an additional $\$ 11$ billion over the next five years to apply to the Moon programme.

Hubble will be an indirect victim of this cost-cutting. NASA decided in 1997 to extend the telescope's life from 2005 to 2010, and astronomers had been lobbying for another extension (see Nature 424, 603; 2003). But O'Keefe told a glum gathering of Hubble researchers and engineers at the Goddard Space Flight Center in Greenbelt, Maryland, that the shuttle will no longer be allowed to visit the telescope, in effect cancelling a 2006 visit by astronauts to add new instruments to the telescope. Observations will probably end sometime after 2007, as its parts begin to fail. The details of Hubble's demise have not been finalized, but a robotic craft is likely to bring it back into Earth's atmosphere, where it would burn up.

O'Keefe said that his decision was based on several factors, including the availability of ground-based telescopes for optical astronomy. But money figured prominently in his thinking. To satisfy recommendations made by the board that investigated the loss of the space shuttle Columbia last February, NASA will have to develop the capability to

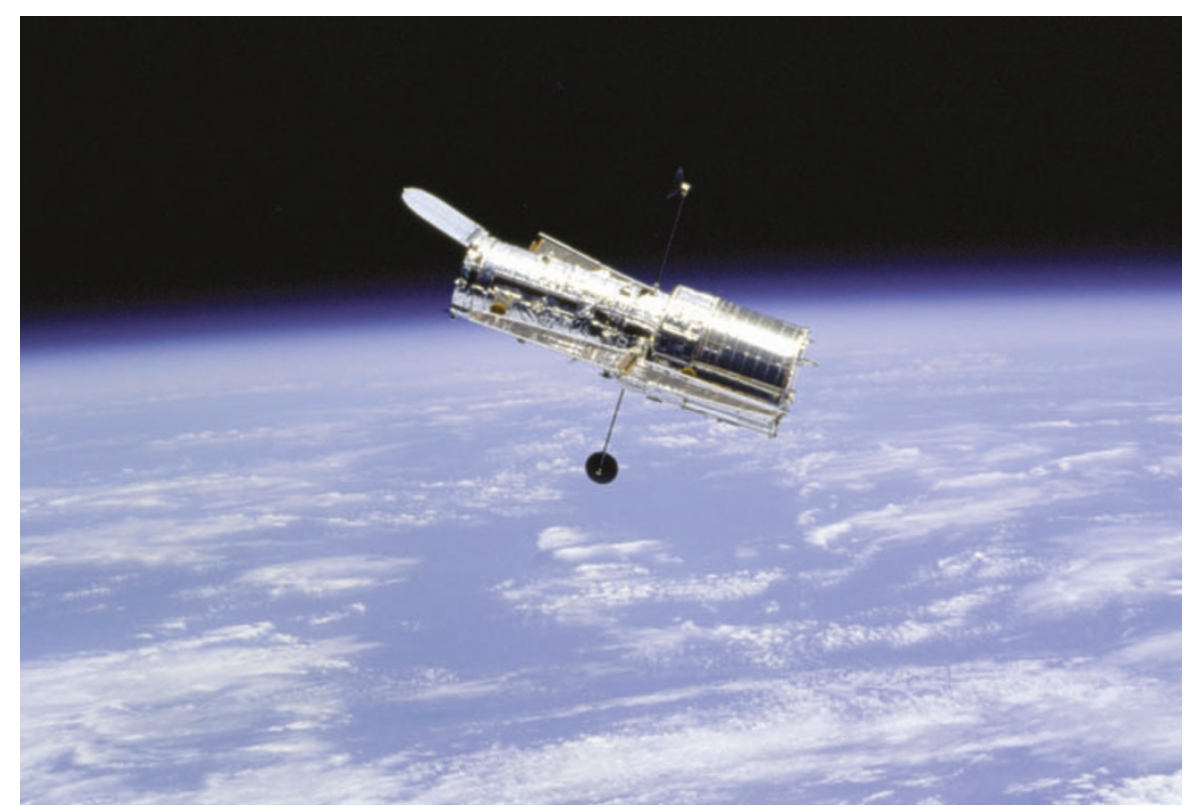

The Hubble Space Telescope will meet a fiery end when it hits Earth's atmosphere sometime after 2007.

inspect shuttles in orbit. That job is relatively easy to do when the shuttle is near the space station, but is more expensive near Hubble, which orbits farther from Earth. Scrapping the 2006 servicing trip to Hubble will avoid these costs, but will also shorten the telescope's lifetime.

Astronomers who use Hubble are not the only group to lose out under Bush's plan. The space station will be complete by 2010 , and NASA will fund research there until 2017. But work in areas not related to human spaceflight, such as materials science, is expected to be greatly reduced or scrapped altogether.

James Pawelczyk, a physiologist at Pennsylvania State University who served on a 2002 panel to prioritize station science, says that the 2017 date still leaves "a fair amount of time to do research", even though key pieces of laboratory equipment will not arrive until 2008 at the earliest. And it is not yet clear, he adds, whether experiments in areas such as the effects of gravity on plants and animals will be considered relevant to the new mandate on human exploration.

Other criticisms have come from sup- porters of space exploration, such as Senator Bill Nelson (Democrat, Florida), a one-time shuttle passenger, who questioned whether funding for the programme will be adequate. But experts contacted by Nature were saying that the numbers seem to add up. Michael Griffin, a former head of NASA's exploration office, says that with NASA management reforms and clever engineering, the $\$ 12$ billion it will have for the first five years "is probably okay".

NASA gave no estimate of the final cost to land people on the Moon, although it would certainly be tens of billions of dollars. Griffin, who now directs In-Q-Tel, a technology firm based in Arlington, Virginia, estimated in congressional testimony last October that NASA would need an additional \$5 billion beyond its annual \$15-billion budget to establish a lunar base within a decade.

If nothing else, Pawelczyk says that the emphasis on human exploration has given the agency a much-needed new focus. "The entire space community has been paralysed" in debates over where to go next, he points out. Bush's decision fixes that in one stroke, he says. "Now it's up to NASA." 